\title{
Owen was right, as Darwin's work continues
}

\section{Tribute to Darwin was not a veiled attack but a genuine expression of hope for the future.}

Sir — In his Words essay "Owen's Parthian shot" (Nature 412, 123; 2001), Kevin Padian discusses a letter from Richard Owen to Spencer Walpole, a politically important member of the British Museum's Board of Trustees, shortly after Charles Darwin's death in 1882. Owen had been asked whether Darwin's scientific accomplishments merited a statue in the new museum. Owen, noting that the decision should be left to the museum's administrators, compared Darwin's singular contributions to biology to those of Copernicus to astronomy. He predicted that Darwin, like Copernicus, would have successors who would complete a fuller understanding of the concepts he had initiated.

Padian claims that in this postmortem analysis and comparison, Owen was aiming "a Parthian shot at his rival in the guise of a tribute - a masterful and delicate duplicity". Duplicity? Hardly. It was an analogy Owen frequently used. The letter reproduced in full in Padian's essay was in fact the last, as far as we know, in a series of four similar letters that began in 1877. In each of these, Owen uses the same analogy to restate figuratively the basic objections he had expressed when Darwin's Origin of Species was first published in 1859: that although natural selection is a valid mechanism to explain species diversification through time, it did not answer the more basic question of the origin of the inheritable individual differences subsequently "naturally selected" for survival in a surrounding and changing environment.

Without an answer to the problem of inherited variations, Owen believed that the origins of species were not fully understood. Darwin himself confessed: "Our ignorance of the laws of variation is profound." With his copernican analogy, Owen was expressing his confidence that in the coming years, as with the heliocentric theory, Darwin's theory of evolution would find its own Galileos,
Keplers and, finally, its Newton.

The twentieth century belonged to the geneticists, who shifted the field from the species level to that of the individual. Ironically, the 1908 meeting in Cambridge to celebrate darwinism provided a platform for the practititoners of the newly named science of genetics, led by William Bateson - those "snarling dogs", complained one loyal darwinian - "to lower Darwin and elevate themselves".

This meeting marked the beginning of the dominance of genetics, with its mutations and its mathematics, leading towards the productive evolutionary syntheses 30 years later.

Among that vast body of creative workers Darwin's work had spawned there were, and are, as Owen's analogy predicted, his Keplers, Galileos and perhaps a Newton.

\section{Jacob W. Gruber}

Department of Anthropology, Temple University, Philadelphia, Pennsylvania 19122, USA

\section{SPOrt to fill a gap on cosmic maps}

Sir - Your well-written and pertinent News Feature (Nature 411, 880-881; 2001) "Raking through the embers" omits to mention the Sky Polarization Observatory (SPOrt), which is a space mission currently under development that is precisely aimed at a sky-polarization survey.

The programme was proposed to the European Space Agency and was selected in 1997 , and is now fully funded by the Italian Space Agency (see http://sport. tesre.bo.cnr.it). SPOrt will be on board the International Space Station for at least 18 months from 2005. It is designed to directly measure Stokes' $Q$ and $U$ parameters at the microkelvin level, providing an accurate measurement of the polarization of the cosmic microwave background (CMB) on a large angular scale $\left(>7^{\circ}\right)$ from four independent channels in the frequency range 22-90 GHz. More than $80 \%$ of the sky will be scanned under the most favourable conditions for testing re-ionization models.

Complementary to the MAP and Planck projects discussed in your feature, which will map the CMB anisotropy with unprecedented accuracy, SPOrt should also provide the much-desired galactic foreground polarization maps so far unobserved at frequencies above a few gigahertz, and study the correlation between the available COBE and MAP temperature maps and polarization patterns over large sky regions. Stefano Cortiglioni Principal investigator, SPOrt project, Istituto di Tecnologie e Studio delle Radiazioni Extraterrestri, Consiglio Nazionale delle Ricerche, Via P. Gobetti 101, 40129 Bologna, Italy

\section{Singapore considers institute's future}

Sir - Your News Feature "Building a biopolis" (Nature 412, 370-371; 2001) quotes Philip Yeo, chairman of the Singapore National Science and Techology Board, as saying that the Institute of Molecular Agrobiology (IMA) has been "a criminal waste of taxpayers' money".

While respecting Yeo's personal view on resource allocation, the Ministry of Trade and Industry, which oversees the board, does not agree with his view. The IMA has done good work and has received international recognition.

Singapore has decided to make the biomedical sciences the focus of its life-science research efforts. The Ministerial Committee on the Life Sciences is now conducting a review of how the IMA should be repositioned with this in mind, and will make a decision later this year, after consulting its international advisers.

Khaw Boon Wan

Ministry of Trade and Industry, 1000 High Street, 09-01 The Treasury, 179434 Singapore

\section{Peers under review}

Sir - Your News Feature "Peers under pressure" (Nature 413, 102-104; 2001) makes me glad that I work in "geology ... [where] complaints are few and far between". I sign all of my reviews, positive and negative, and people still talk to me.

Some of the cited examples of foul play by reviewers have obviously had major implications for tenure, patent rights and so on. No wonder, then, that some are tempted to seek a legal solution to some of the injustices that the peerreview system has enabled the less scrupulous to perform.

Problems could doubtless arise in the process of separating genuine complaints from the paranoid or vindictive, and the accused might launch countersuits and writs. But a few successful prosecutions might well encourage wrongdoers to consider changing their ways.

Stephen K. Donovan

Department of Palaeontology, Nationaal Natuurhistorisch Museum/Naturalis, Postbus 9517, 2300 RA Leiden, The Netherlands 